\title{
DEMOCRACIA E FORMAÇÃO HUMANA: A DIMENSÃO IDEOLÓGICA DESTES CONCEITOS NO CONTEXTO DA SOCIEDADE CAPITALISTA
}

\author{
Anita Helena Schlesener ${ }^{1}$
}

\section{Resumo:}

O presente artigo tem o objetivo de analisar a formação do senso comum no contexto da sociedade capitalista, tendo como referencial teórico escritos de Marx e de Gramsci. Abordamos a dimensão ideológica da política implícita na forma de pensar comum e no modo como assimila conceitos sem crítica. Explicitam-se os limites e possibilidades das noções de democracia e de formação humana, tendo como horizonte a luta de classes. $\mathrm{O}$ aspecto educativo se expressa na superação da aparência do empírico imediato para mostrar as relações de força que este imediato oculta. $\mathrm{Na}$ abordagem dialética o empírico não é o imediatamente dado, que se constitui em aparência do real, mas sim o fato em seu contexto, enquanto elemento de uma estrutura social determinada, com uma dimensão histórica pela qual se produz o movimento da vida material e espiritual. A formação humana não pode se realizar em uma sociedade dividida e marcada pela extrema desigualdade social como é a sociedade capitalista.

Palavras-Chave: Estado, democracia, formação humana, ideologia, educação.

\section{DEMOCRACY AND HUMAN FORMATION: THE IDEOLOGICAL DIMENSION OF THESE CONCEPTS IN THE CONTEXT OF CAPITALIST SOCIETY}

\begin{abstract}
:
The aim of this paper is to analyze the formation of common sense in the context of capitalist society, having as theoretical reference the writings of Marx and Gramsci. We address the ideological dimension of politics implicit in the common way of thinking and the way it assimilates concepts without any kind of criticism. By appointing class struggle as horizon, the limits and possibilities of notions such as democracy and human formation are here explained. The educational aspect is expressed by the overcoming of the appearance of the immediate empirical one in order to show the relations of forces concealed within this immediate. From a dialectical approach, the empirical one is not that immediately given, constituted trough the appearance of the real, but rather the fact in its context, as an element of a given social structure, with a historical dimension through which the movement of material and spiritual life takes place. Human formation cannot take place in a divided and marked by extreme social inequality society as it is the capitalist society.
\end{abstract}

\footnotetext{
${ }^{1}$ Professora de filosofia política e de estética da UFPR; atualmente docente do Programa de Mestrado e Doutorado em Educação da UTP de Curitiba; Pós-doutorado em Educação na UNICAMP. E-mail: anita.helena@libero.it.
} 
Key Words: State, democracy, human formation, ideology, education.

\section{Introdução:}

As premissas de que partimos não constituem bases arbitrárias, nem dogmas; são antes bases reais de que só é possível abstrair no âmbito da imaginação (MARX e ENGELS, 1976, p. 18).

O presente artigo pretende partir do empírico que, para nós, já se apresenta como um modo de ser permeado por um determinado pensamento, em geral, oculto, ou seja, um pensamento do qual o senso comum desconhece a origem e a formação, mas que aceita como verdade consagrada. A partir deste contexto, pretende-se explicitar conceitos como democracia e formação humana, salientando sua dimensão ideológica. O referencial básico para esta reflexão são alguns escritos de Marx e de Gramsci. As questões que norteiam este trabalho são: como os conceitos se elaboram no senso comum, formando o imaginário social e dando sustentação ao poder vigente? Existem possibilidades de responder aos interesses das classes subalternas no contexto estrutural da democracia burguesa? Qual a força e também a fragilidade do Estado liberal, que se mantém ainda hoje na formação do senso comum? Qual a importância da educação para a formação política e humana das classes subalternas?

Iniciamos com observações sobre o senso comum, base empírica e ponto de partida para o materialismo histórico, assim como abordado por Gramsci, cujas indagações se inserem no âmbito de duas questões fundamentais: a) como ocorrem as relações de força na manutenção da hegemonia; b) como as classes trabalhadoras podem superar os limites do senso comum a partir das lutas por uma nova ordem social e política. A primeira questão nos remete ao modo como funciona a ideologia; a segunda se evidencia na importância de se entender a formação do senso comum para formar "vontades coletivas permanentes", ou seja, para sair do imediatamente cotidiano e individual e criar condições para a formação de uma unidade política com o objetivo de uma ação coletiva unitária.

Trata-se, portanto, de entender a formação ideológica do senso comum e, principalmente como, nele, atuam a religião e a filosofia no processo de formação do modo de pensar e da concepção de verdade. "O senso comum não é uma coisa rígida e imóvel, mas se transforma continuamente enriquecendo-se de noções científicas e opiniões filosóficas que entram no costume". Porém, na medida em que assimila

\begin{tabular}{|l|l|l|l|l|}
\hline Q Rovista Dialectus & Ano 4 & n. 10 & Janeiro - Julho 2017 & p. 24-45 \\
\hline
\end{tabular}


conceitos sem conhecer a sua origem e o processo de sua produção, os assimila de modo abstrato, de tal forma que cria, neste movimento, "uma fase mais ou menos enrijecida de um certo tempo e lugar (seria necessário fixar bem estes conceitos repensando-os a fundo)". Assim consolidado, o senso comum aproxima-se ao folclore, ou seja, torna-se um modo de pensar que orienta a vida mais ou menos inconscientemente (Q. 1, p. 76).

Ao criticar o Ensaio popular de Bukharin, principalmente no modo como este autor se apoia no senso comum, Gramsci acentua que o "traço fundamental e mais característico é o de ser uma concepção (também nos cérebros individuais) desagregada, incoerente, inconsistente, de acordo com a posição social e cultural das multidões das quais ele é a filosofia”. Neste contexto, uma teoria que se pretenda materialista histórica não pode referendar o senso comum, mas sim fazer a sua crítica (Q. 11, p. 1396).

Ainda no mesmo fragmento (parágrafo 13), Gramsci ressalta que os "principais elementos do senso comum são fornecidos pelas religiões”, elementos estes misturados com "elementos 'realistas', materialistas", enquanto "produto imediato da sensação bruta", ou seja, imediata, o que não contradiz o elemento religioso, porque este também se constitui de elementos “ 'supersticiosos' e acríticos” (Q. 11, p. 1396-1397). Deste modo, o senso comum, por assimilar ideias de forma abstrata e fragmentária, tem um caráter muitas vezes dogmático e difícil de desconstruir.

A "certeza " do senso comum se enraíza na religião, ou seja, numa ideologia muito difundida, mas que se funda em elementos que não podem ser provados ou demonstrados (Q. 11, p. 1455). Em outras palavras, o senso comum se sedimenta ou no imediatamente dado ou no transcendental abstrato, formando suas opiniões não com base em raciocínio lógico, mas em crenças assumidas por motivos de fé. Sua visão "materialista" não é histórica, mas sim metafisica. Esta questão tem uma dimensão política de grande alcance, que Gramsci desvela na formação do fascismo italiano e também na consistência que assume o pensamento liberal ao longo dos séculos, mesmo não tendo, ao longo de todo este tempo, representado a forca política dominante.

Ao partir da configuração do senso comum pretende-se retomar as primeiras reflexões de Marx sobre a ideologia expressas nos escritos de 1843-1844 e que, a partir da leitura de Feuerbach, iniciam a explicitação do conceito de emancipação humana e da sua impossibilidade de se realizar por meio do Estado ou no contexto do capitalismo, percepção que o leva a entender que Hegel efetuou uma importante crítica, mas era preciso ir mais além superando os limites da crítica e do Estado burguês, em direção ao

\begin{tabular}{|l|l|l|l|l|}
\hline Rovista Dialectus & Ano 4 & n. 10 & Janeiro - Julho 2017 & p. 24-45 \\
\hline
\end{tabular}


que Marx denomina "democracia radical". Neste momento a tarefa emancipadora de todas as formas de dominação é ainda a filosofia, mas a ideia de ideologia retirada da crítica religiosa de Feuerbach estende-se às relações sociais efetivas, expressas na economia e na política que, ao longo dos escritos posteriores, assumem a dimensão de práxis.

Deste movimento, tem-se as reflexões de A Ideologia Alemã, na definição clara da aparência da situação empírica na qual a "produção de ideias, de representações e da consciência está direta e intimamente ligada à atividade material", que "é a linguagem da vida real" (MARX e ENGELS, 1976, p. 26). Entretanto, não aparecem como tal em função das condições históricas que as produziram. Retomamos alguns aspectos desta reflexão detendo-nos um instante na noção de ideologia a fim de explicitar, num segundo momento, as noções de democracia e formação humana, seus limites e possibilidades no contexto da sociedade capitalista.

As conclusões de Marx são conhecidas: se as ideias se enraízam na prática material e social, não será a crítica intelectual a resolver o problema, mas sim a praxis revolucionária. Entretanto, sem a crítica não se transforma a prática e ambas, bem dosadas e articuladas, podem abrir novas sendas de transformação.

Os passos seguintes são: mostrar os limites e possibilidades da democracia burguesa e da ideia de formação humana no contexto da sociedade capitalista, questões que tem como base os escritos de Gramsci e a noção de hegemonia. A partir desta explanação, retoma-se a questão da educação nos caminhos da luta de classes.

\section{Notas sobre a noção de ideologia:}

As reflexões de Marx sobre a ideologia se iniciam na medida em que Marx toma conhecimento da crítica de Feuerbach a propósito da religião. Um dos textos em que a questão é introduzida é Sobre a Crítica da Filosofia do Direito de Hegel. Introdução, escrito em fins de 1843 e início de 1844. Trata-se de um escrito carregado de metáforas que mostra como a realidade alemã se encontra efetivamente de cabeça para baixo: a burguesia alemã se encontrava frente à necessidade de realizar a sua revolução, mas numa situação diversa daquela francesa do século anterior, visto que a classe operária começava a despontar como a grande força revolucionária. Neste contexto, a burguesia alemã assume posições conservadoras, de modo que a "arma da crítica" que a filosofia alemã propiciava precisava da "crítica das armas", ou seja, a teoria precisava tornar-se a

\begin{tabular}{|c|c|c|c|c|}
\hline Rovista Dialectus & Ano 4 & n. 10 & Janeiro - Julho 2017 & p. 24-45 \\
\hline
\end{tabular}


força movente da ação transformadora, realizando a emancipação humana universal (MARX, 2009, p. 475).

Para tanto, necessário se fazia superar as contradições cuja expressão maior estava na religião: a "miséria religiosa é, em si, a expressão da miséria real e, também, o protesto contra a miséria real", ou seja, uma situação contraditória que se traduzia em mistificação e, ao mesmo tempo, em questionamento. É neste escrito que se define a religião como "o ópio do povo", a "felicidade ilusória do povo", que precisa ser abolida para se efetivar a "sua real felicidade". Para tanto, coloca-se a "exigência de abandonar as ilusões sobre uma situação é a exigência de abandonar uma situação que necessita de ilusões" (MARX, 2009, p. 475), ou seja, de transformar a realidade em questão.

Temos, aqui, dois pontos fundamentais: primeiro, a colocação de que a ideologia, é uma ilusão sobre o real, cuja expressão maior é a religião; segundo que, para superar a ideologia, é preciso abandonar a situação geradora da ilusão, ou seja, mudar a realidade. A partir destas constatações, Marx coloca as bases da crítica aos neohegelianos, afirmando que a teoria deve ir mais além do que "desfolhar as flores imaginárias dos grilhões", ou seja, deve fazer a crítica não para que os homens suportem tais grilhões, "mas para que se libertem deles e apanhem a flor viva". Colocase a necessidade de "libertar o homem da ilusão para que ele pense, aja e configure sua realidade como alguém que reconquistou a razão (...)”; para que o homem, enfim, deixe de crer numa verdade transcendente e estabeleça a "verdade daquilo que o circunda". A crítica dos céus precisa se transformar na "crítica da terra, a crítica da Religião na crítica do Direito, a crítica da Teologia na crítica da Política” (MARX, 2009, p. 475).

Este escrito é importante ainda porque, concentrando-se no movimento político alemão, parece prenunciar as reflexões posteriores sobre a contrarrevolução alemã: para os alemães, "é instrutivo ver o ancien régime, que na história representou uma tragédia, desempenhar um papel cômico como fantasma alemão" (...) O "ancien régime moderno é somente o comediante de uma ordem mundial cujos reais heróis já faleceram”. A imagem histórica ou o imaginário social passa por várias fases antes de ser superado e a última fase também a comédia, "para que a humanidade se despeça hilariamente de seu passado" (MARX, 2009, p. 478-479). São metáforas que parecem antecipar a ideia explícita em $O 18$ Brumário de Luís Bonaparte, assim como o entendimento posterior de que, enquanto as revoluções burguesas se sustentam em uma retomada do passado, as revoluções operárias precisam ser radicais, ou seja, acertar as contas com o passado a

\begin{tabular}{|l|l|l|l|l|}
\hline Qenista Dialectus & Ano 4 & n. 10 & Janeiro - Julho 2017 & p. 24-45 \\
\hline
\end{tabular}


fim de criar as condições de uma transformação pela raiz subvertendo a ordem de todas as coisas.

"Na política, os alemães pensaram o que os outros povos efetivaram". (...) "ser radical é tocar a questão na raiz" e a "raiz é o próprio homem"; cabe acrescentar, o homem em situação. A teoria precisa ser radical e, para tanto, precisa atingir as massas, emancipar o homem dos grilhões, explicitar as contradições do real para uma efetiva transformação (MARX, 2009, p. 482-483). Estes pontos nos revelam que tanto a teoria da ideologia quanto a da revolução já se encontram nestas primeiras anotações e o trabalho que Marx desenvolveu ao longo da vida se constituiu em explicitar estas questões.

Neste percurso, tem-se como uma das afirmações de Marx e Engels mais citadas quando se trata da questão da ideologia, dando uma nova dimensão política ao imaginário social: em A Ideologia Alemã, trata-se não apenas de uma ilusão que encobre as contradições do real, mas de uma efetiva relação de dominação: os "pensamentos da classe dominante são também, em todas a épocas, os pensamentos dominantes" e que a classe social que detém o poder material na sociedade, detém também o poder espiritual: os "pensamentos dominantes são apenas a expressão ideal das relações materiais dominantes", são as ideias que sustentam o domínio de classe (MARX e ENGELS, 1976, p. 55-56).

Os indivíduos que constituem a classe dominante possuem entre outras coisas uma consciência e é em consequência disso que pensam: na medida em que dominam enquanto classe e determinam uma época histórica em toda a sua extensão, é lógico que esses indivíduos dominem em todos os sentidos, que tenham, entre outras, uma posição dominante como seres pensantes, como produtores de ideias que regulamentem a produção e a distribuição dos pensamentos de sua época; as suas ideias são, portanto, as ideias dominantes da sua época (MARX e ENGELS, 1976, p. 56).

E, aprofundando sua análise das condições históricas de surgimento das ideias, mostram que, a partir da divisão social do trabalho, que produz a divisão entre trabalho material e trabalho intelectual, inclusive os intelectuais que produzem e divulgam as ideias da classe dominante, são envolvidos pelas ilusões que a classe dominante tem de si própria. Tanto no seio da classe quanto entre os intelectuais surgem contradições e conflitos gerados pela ilusão "de que as ideias dominantes não são as ideias da classe

\begin{tabular}{|l|l|l|l|l|}
\hline Q Rovista Dialectus & Ano 4 & n. 10 & Janeiro - Julho 2017 & p. 24-45 \\
\hline
\end{tabular}


dominante e de que tem um poder distinto do poder dessa classe" (MARX e ENGELS, 1976, p. 57). Ou seja, se no escrito Sobre a Crítica da Filosofia do Direito de Hegel. Introdução, os autores acentuam as características da ideologia no senso comum, aqui mostram a dimensão da ideologia na própria formação dos intelectuais, nas ilusões dos neohegelianos que pretendiam fazer mudanças apenas com a crítica. E seguem mostrando os estratagemas para sustentar a ilusão de que são as ideias que dominam a história, o esforço místico para conceber a autodeterminação dos conceitos, agora afastados de sua dimensão empírica. ${ }^{2}$

Depois de separar as ideias dominantes dos indivíduos que exercem o poder e sobretudo das relações que decorrem de um dado estádio do modo de produção, é fácil concluir que são sempre as ideias que dominam na história, podendo-se então abstrair, destas diferentes ideias, a 'Ideia', ou seja, a ideia por excelência, etc., fazendo dela o elemento que domina na história (...) (MARX e ENGELS, 1976, p. 58-59).

A partir destes pressupostos, pode-se representar Deus, Homem, Humano, tudo o que se imaginar, apresentando como universal válido para todos os tempos; deste modo, pode-se criar a ilusão de que as ideias é que dominam e não uma determinada classe social. Daí a naturalizar os conceitos, como acontece no senso comum, é um passo.

Estas questões são retomadas e reinterpretadas por Gramsci a fim de fazer a crítica à ideologia enquanto instrumento de dominação consolidado no senso comum. Sabe-se que A Ideologia Alemã foi publicada em 1932 e Gramsci teve acesso a este escrito, parcialmente e de forma indireta na leitura do Prefácio de 1859 e por meio de uma carta de Engels endereçada a Franz Mehring, datada de 14/07/1893, onde se aborda a questão da ideologia. Neste Prefácio Marx praticamente retoma e aprofunda a questão da ideologia do escrito de 1843-1844, explicitando as relações entre estrutura e superestrutura para mostrar a inversão que acontece na produção das formas ideológicas e sua expressão na consciência de si e do mundo, de modo que:

\footnotetext{
${ }^{2}$ Em O 18 Brumário de Luís Bonaparte o primeiro capítulo marca posição ante o pensamento de Hegel: "Hegel observa em uma de suas obras que todos os fatos e personagens de grande importância na história do mundo ocorrem, por assim dizer, duas vezes. Esqueceu- se de acrescentar: a primeira como tragédia e a segunda como farsa" (MARX, 1977, p. 17). E, na sequência, Marx esclarece a natureza do "esquecimento" de Hegel, que resulta dos limites ideológicos nos quais esse grande filósofo estava inserido.
}

\begin{tabular}{|l|l|l|l|l|}
\hline Qenista Dialectus & Ano 4 & n. 10 & Janeiro - Julho 2017 & p. 24-45 \\
\hline
\end{tabular}


Assim como não se julga o que um indivíduo é a partir do julgamento que ele se faz de si mesmo, da mesma maneira não se pode julgar uma época de transformação a partir de sua própria consciência; ao contrário, é preciso explicar esta consciência a partir das contradições da vida material, a partir do conflito existente entre as forças produtivas sociais e as relações de produção (MARX, 1974, p. 136).

Trata-se de superar a aparência do empírico imediato e explicitar as relações de força que este imediato oculta. $\mathrm{O}$ que nos interessa aqui é esclarecer a dimensão que assume a ideologia no âmbito do senso comum e como este conceito se integra na formulação da noção de hegemonia, na qual a dominação não se expressa apenas como força explícita ou por meio dos mecanismos de expropriação econômica, mas principalmente pela formação de uma concepção de mundo homogênea expressa no consenso passivo das massas. Se os intelectuais da classe dominante não têm a dimensão ideológica de suas ideias, imagine-se as pessoas comuns, alimentadas cotidianamente pelos meios de comunicação de massa e pelas diversas religiões existentes.

Desmistificar as bases das relações de poder que consolidam a hegemonia da classe dominante exige explicitar os mecanismos de dominação intelectual mostrando seus limites na formação do senso comum, no qual os conceitos são assimilados de forma abstrata, a partir das derivações religiosas, da imediaticidade da experiência e do discurso de meias verdades ou de ocultamento das contradições reais que fazem parte da ordem social. "A inovação fundamental introduzida pela filosofia da praxis na ciência da política e da história é a demonstração de que não existe uma 'natureza humana' abstrata, fixa e imutável”, mas o humano é fruto das relações sociais, da tradição e do contexto histórico e uma teoria política precisa buscar o conteúdo concreto, ou seja, as relações materiais de existência, em suas contradições e limites, que dão sustentação ao modo de pensar em determinado momento histórico (GRAMSCI, 1978, Q. 13, p. 1598).

As relações econômicas, sociais e políticas precisam ser entendidas na articulação dialética em que são produzidas formando o que Gramsci denomina "bloco histórico", no qual "as forças materiais são o conteúdo e as ideologias a forma; a distinção entre forma e conteúdo é meramente didática visto que as forças materiais não seriam concebíveis sem forma" e as ideologias seriam meras fantasias sem a base de sustentação material (GRAMSCI, 1978, Q. 7, p. 869).

\begin{tabular}{|l|l|l|l|l|}
\hline Q Rovista Dialectus & Ano 4 & n. 10 & Janeiro - Julho 2017 & p. 24-45 \\
\hline
\end{tabular}


As ideias se personificam na prática, nos hábitos e na tradição que alimentam o modo de pensar cotidiano; é também na prática que se atribui uma verdade objetiva ao pensamento na medida em que se reconhecem as contradições e o empírico toma uma nova dimensão revelando o que se esconde sob a aparência do imediatamente dado, ou seja, as ideias tomam um valor de conservação ou de transformação do real. A “proposição contida na Introdução à Crítica da Economia Política, que os homens tomam consciência dos conflitos da estrutura no terreno das ideologias, deve ser considerada como uma afirmação de valor gnosiológico e não puramente psicológico e moral (GRAMSCI, 1978, Q. 10, p. 1249).

Acentuar o valor gnosiológico da afirmação de Marx significa não apenas posicionar o marxismo diante das ideologias modernas, mas mostrar a nova dimensão da filosofia da praxis, que consiste em articular economia, política e história, a fim de mostrar a relação dialética entre material e espiritual, de modo que as verdades não são neutras e dadas de uma vez por todas, mas são historicamente construídas a partir do modo como se constrói a sociedade. Sem compreender esta relação torna-se "impossível compreender a filosofia da praxis, sua posição ante o idealismo e o materialismo mecânico e a importância e significação da doutrina das superestruturas" (GRAMSCI, 1978, Q. 11, p. 1420).

Esta leitura de Gramsci objetiva a crítica ao duplo revisionismo de Marx, tanto na forma do materialismo mecanicista que se firmou principalmente a partir do ensaio de Bukharin, quanto na vertente idealista na mescla de hegelianismo, representada na Itália por Croce. Na medida em que se posiciona criticamente ante estas duas leituras, Gramsci também explicita o sentido da hegemonia marcando posição ante o liberalismo e, principalmente, acentuando a necessidade de superar o senso comum no sentido de esclarecer a dimensão ideológica no contexto da luta de classes.

Assim, em outros momentos dos cadernos, como o fragmento do Cadernos 10, Gramsci pergunta: "o que é o homem?" E acentua que não deseja saber a definição genérica, nem a definição singular individual, ou seja, posiciona-se claramente contra a noção que deriva de uma essência como verdade absoluta e contra o relativismo que se concentra no singular imediato. Para entender o que é o homem, precisamos situá-lo num contexto determinado, numa relação histórica com o meio natural e social do qual faz parte: o "homem não entra em relação com a natureza simplesmente pelo fato de ser ele próprio natureza, mas ativamente, por meio do trabalho e da técnica”, atividade pela qual "cada um transforma a si próprio, se modifica, na medida em que transforma e

\begin{tabular}{|l|l|l|l|l|}
\hline Q Rovista Dialectus & Ano 4 & n. 10 & Janeiro - Julho 2017 & p. 24-45 \\
\hline
\end{tabular}


modifica todo o conjunto de relações do qual ele é o centro de ligação"; na medida em que trabalha, modifica a natureza, constrói relações, o homem transforma também o seu modo de pensar (GRAMSCI, 1978, Q. 10, p. 1345).

É isso que define também o que é humano: a linguagem é política e metafórica, fato que é desconhecido do senso comum; as palavras não são neutras, ao contrário, muitas vezes expressam ou ocultam interesses ligados ao exercício do poder fortalecendo as relações de poder vigentes. Muitos conceitos usados no senso comum são naturalizados pela grande influência do positivismo no modo de pensar cotidiano, mas também apresentam um significado imediato, parcial e, por isso, abstrato. Muitos que usam conceitos como "liberdade", "paz", "justiça", "democracia”, não sabem precisamente do que realmente estão falando. Desta forma, os conceitos possuem um poder místico, mistificador, que oculta os conflitos, as desigualdades sociais, a expropriação do trabalho e tudo o que mantém ideologicamente esta sociedade. $\mathrm{Na}$ medida em que se fortalece, na sociedade contemporânea, o ideário conservador, as palavras passam a funcionar como reguladoras das relações sociais e o ocultamento dos conflitos se torna ainda mais presente, as palavras funcionando como censoras. Pensemos no que se chama hoje de "politicamente correto", modo de falar que se compõe de uma série de eufemismos que visam a silenciar ou ocultar os conflitos, assumindo uma dimensão política de grande efeito ideológico.

Quais as possibilidades de superar, no senso comum, a abstração dos conceitos? A questão é complexa e envolve tanto a perspectiva política de organização dos movimentos sociais pela qual se forma a consciência crítica e luta por transformações radicais, quanto os mecanismos de educação que a sociedade oferece, entre eles, todo o sistema escolar. A mudança estrutural que possibilitaria a transformação do senso comum precisaria ter a dimensão de uma revolução copernicana, ${ }^{3}$ ou seja, um movimento econômico e político que conseguisse alterar o modo de pensar. Uma das questões desse processo de formação implica reaprender a compreender o real para além das aparências, o que exigiria sair dos limites da lógica formal para a lógica dialética, ou seja, iniciar pelo método - empírico, teórico, empírico - para mostrar a possibilidade de superar a abstração dos conceitos. Quando se parte do empírico se precisa entender que não se trata do imediatamente dado, que se constitui em aparência

\footnotetext{
${ }^{3}$ No sentido da crítica marxiana a todo o pensamento filosófico ate então produzido; descer do céu para a terra, ou seja, mudar a abordagem do conhecimento abandonando a discussão dos fundamentos universais para fixar-se na realidade efetiva e concreta, no processo contraditório de formação da sociedade.
}

\begin{tabular}{|l|l|l|l|l|}
\hline Qovista Dialectus & Ano 4 & n. 10 & Janeiro - Julho 2017 & p. 24-45 \\
\hline
\end{tabular}


do real, mas sim em considerar os fatos em seu contexto, enquanto elemento constitutivo de uma estrutura social determinada, com uma dimensão histórica pela qual se produz o movimento da vida material e espiritual. Trata-se de superar tanto o discurso metafisico quanto o positivista, segundo os quais existem verdades universais legitimadoras da situação vigente ou, o que se aproxima mais do senso comum, leis naturais que regem o social. Para Marx, partir do empírico significa abordar o homem e a sociedade a partir de sua historicidade, em cujo movimento as contradições se produzem, se consolidam e se superam.

Nesta dimensão empírica que caracteriza a existência humana, o teórico se produz concomitantemente com a produção da vida cotidiana, ou seja, ante o senso comum a "filosofia da praxis tem, inicialmente, uma posição polêmica e crítica", a fim de mostrar os limites de um pensamento naturalizado e abstrato, ou seja, para a "superação do modo de pensar precedente e do pensamento concreto existente (o mundo cultural existente)" (GRAMSCI, Q. 11, 1978, p. 1383). E Gramsci desenvolve toda uma reflexão sobre de onde partir, como fazer esta crítica partindo do senso comum para superá-lo, acentuando que se trata de um processo de educação que implica, antes de tudo, um movimento de organização política das massas. Na medida de suas lutas e de sua organização política é que as classes trabalhadoras podem criar as condições de reconhecer as contradições que permeiam o seu cotidiano, os limites de um pensamento assimilado de modo aleatório e fragmentado, o peso das tradições, os limites das religiões, enfim, formar uma nova concepção de mundo coerente e unitária. Não é tarefa de pequena monta, visto que implica "criticar toda a filosofia até hoje existente, na medida em que ela deixou traços consolidados na filosofia popular" (GRAMSCI, 1978, p. 1371).

\section{A democracia no contexto da sociedade burguesa:}

A partir dos pressupostos acima, falar de "democracia" implica perguntar de qual democracia se fala; certamente da única que vivenciamos, a democracia burguesa. Partindo do pensamento de Gramsci, a ideia de democracia burguesa se vincula ao modo de organização do Estado parlamentar, tendo como pressuposto a separação que o pensamento liberal, que permeia o senso comum, estabelece entre economia e política, reduzindo esta à mera função de governo. Sustentada pela estrutura jurídica, a ideia de democracia é reduzida a um conjunto de práticas meramente formais, na medida em que

\begin{tabular}{|l|l|l|l|l|}
\hline Q Rovista Dialectus & Ano 4 & n. 10 & Janeiro - Julho 2017 & p. 24-45 \\
\hline
\end{tabular}


o direito não expressa os interesses gerais da sociedade porque omite a desigualdade social: "supõe-se que o direito seja expressão integral de toda a sociedade, o que é falso"; (...) o "direito não exprime toda a sociedade, mas sim a classe dirigente, que ‘impõe’ para toda a sociedade aquelas normas de conduta que estão mais ligadas à sua razão de ser e ao seu desenvolvimento" (Q. 6, p. 773).

Uma das funções do direito é ideológica, ou seja, pressupor que todos são iguais quando, na realidade, a desigualdade é o entrave para o livre acesso aos direitos garantidos para todos. Do ponto de vista político, a afirmação da igualdade formal gera a crença de que "todos podem tornar-se elementos da classe dirigente" (Q. 6, p. 773), o que se mostra ilusório. Agrega-se a isso o fato de que a ideia de igualdade se firma no imaginário social a partir de um discurso que pretende garantir interesses individuais subjetivos sem relação com a situação em que este sujeito está inserido, ou seja, sem abordar os limites sociais que determinam o acesso aos direitos. Porém, estes pressupostos permitem construir determinadas relações de hegemonia que garantem a aceitação da ordem vigente e o livre exercício das formas de dominação pela classe dominante. Ampliam-se, assim as funções ideológicas do direito principalmente por seu caráter educativo, de gerar um conformismo social: “por meio do 'direito', o Estado torna 'homogêneo' o grupo dominante e tende a criar um conformismo social útil ao desenvolvimento do grupo dirigente" (Q. 6, p. 757).

Outro elemento mistificador da ideia de democracia é a própria estrutura do Estado que, a partir da influência do liberalismo (e do positivismo) no senso comum, é reduzida ao aparato administrativo e burocrático que constitui a esfera do poder governamental, fato que apresenta sérias implicações no entendimento da democracia. Trata-se de:

... um erro teórico cuja origem prática não é difícil de identificar, ou seja: baseia-se na distinção entre sociedade política e sociedade civil que, de distinção metódica, é transformada e apresentada como distinção orgânica. Assim, afirma-se que a atividade econômica é própria da sociedade civil e que o estado não deve interferir em sua regulamentação $(Q$. 13, p. 1589-90).

Para Gramsci, a estrutura do Estado se compõe da articulação entre sociedade política e sociedade civil, ou seja, o Estado abrange o conjunto da sociedade, em suas relações econômicas, sociais e políticas. Porém, a consolidação da concepção liberal,

\begin{tabular}{|l|l|l|l|l|}
\hline Rovista Dialectus & Ano 4 & n. 10 & Janeiro - Julho 2017 & p. 24-45 \\
\hline
\end{tabular}


que separa forma de conteúdo, gera a crença de que o Estado se constitui apenas pelo aparato administrativo e burocrático, separado da sociedade civil que, no pensamento comum é o espaço das empresas (econômicas), da família, da escola, das igrejas, etc. "assim se afirma que a atividade econômica é própria da sociedade civil e que o Estado não deve intervir na sua regulamentação". Porém, na "realidade efetiva sociedade civil e Estado se identificam”. A separação libera o sistema econômico de qualquer controle, sem mostrar que o liberalismo é, também ele, “uma 'regulamentação' de caráter estatal, introduzida e mantida por via legislativa e coercitiva" (Q. 13, p. 1590).

No Caderno 10, a propósito do significado político da expressão "homem econômico", Gramsci esclarece mais uma vez a natureza do Estado moderno, afirmando que "o Estado é o instrumento para adequar a sociedade civil à estrutura econômica" (Q. 10, p. 1254). Esta colocação pode ser completada com a observação do Caderno 6, onde Gramsci observa que na "noção geral de Estado entram elementos que também são comuns à noção de sociedade civil (Estado = sociedade política + sociedade civil, isto é, hegemonia revestida de coerção)" (Q. 6, p. 763-764), ou seja, "por Estado deve entender-se, além do aparato de governo, também o aparato 'privado' de hegemonia ou sociedade civil” (Q. 6, p. 801).

A separação entre sociedade política e sociedade civil reproduzida no imaginário social permite que se aceite passivamente que uma ordem político-jurídica formal tutele a "ordem pública e o respeito às leis" deixando livre as empresas e o mercado para se autorregularem ou agirem sem qualquer regulamentação (Q. 26, p. 2302). Trata-se de acentuar aqui a dimensão ideológica e mistificadora do pensamento liberal que alimenta o senso comum e determina o significado de "democracia" no contexto da sociedade capitalista.

Outro limite para o funcionamento da democracia burguesa é o sistema parlamentar: a separação entre sociedade política e sociedade civil e entre forma e conteúdo, ou seja, uma organização política que se sustenta sobre uma igualdade formal dos indivíduos e ignora a a verdadeira realidade de extrema desigualdade social gerada pelo modo de produção capitalista produz um sistema representativo paradoxal; um sistema que se legitima com o voto popular, mas não expressa a vontade popular, na medida em que a verdadeira representação se faz em favor do poder econômico, cuja ingerência se faz desde a forma de constituição dos partidos e do processo eleitoral e se estende no curso do mandato.

\begin{tabular}{|l|l|l|l|l|}
\hline Rovista Dialectus & Ano 4 & n. 10 & Janeiro - Julho 2017 & p. 24-45 \\
\hline
\end{tabular}


Para Burgio (2014, p. 338-339), já nos escritos de de 1819-1920 Gramsci considera o "aparelho institucional do Estado parlamentar um bloco funcional para a manipulação da opinião pública e da vontade coletiva, ou seja, para a salvaguarda do aparato de poder instituído”. Para o “jovem Gramsci, a ‘democracia burguesa' repousa sobrea cisão entre a esfera política e a realidade social, cisão que o sistema 'parlamentar' tem a função de mascarar, legitimar e perpetuar". Podemos acentuar que os fatores que geram esta possibilidade são, principalmente, a separação entre dirigentes e dirigidos que se encontram na base da abstração dos conceitos no senso comum, a separação entre sociedade politica e sociedade civil na concepção de Estado e a estrutura parlamentar sedimentada na separação entre forma e conteúdo.

Gramsci identifica estes problemas a propósito da vida nacional francesa (desde a revolução burguesa até Luís Bonaparte) onde examina a posição de Jacques Bainville sobre o sufrágio universal e o plebiscito e afirma que estes "são concebidos como esquemas abstratos", independentes "das condições de tempo e lugar". Naquela situação histórica, "toda ratificação dada pelo sufrágio universal e pelo plebiscito" supunham a concentração da classe fundamental em torno de uma personalidade "cesarista", sendo que existiram outras formas de sufrágio universal, "na medida em que se modificaram historicamente as relações econômico-políticas” (Q. 13, p. 1648).

Cabe acentuar que não se trata de desqualificar o sistema representativo, mas de mostrar que, no contexto da democracia burguesa, na medida em que se omite a desigualdade social e se separa forma de conteúdo, este sistema funciona como um mecanismo de mistificação da política, de exercício da demagogia para a manipulação da vontade popular em favor de interesses de classe. Trata-se de buscar a articulação da estrutura democrática burguesa com o exercício da hegemonia, ou seja, de mostrar como, no contexto da sociedade capitalista, funcionam as relações de poder que se sustentam no Estado.

Entre os muitos significados de democracia, o mais realista e concreto me parece se possa encontrar em conexão com o conceito de hegemonia. No sistema hegemônico existe democracia entre o grupo dirigente e os grupos dirigidos na medida em que [o desenvolvimento da economia e, portanto] a legislação [que expressa este desenvolvimento] favorece a passagem [molecular] dos grupos dirigidos ao grupo dirigente (Q. 8, p. 1056). 
A democracia realista e concreta se funda nesta possibilidade de "passagem molecular" da situação de dirigido para a situação de dirigente. Isso pode acontecer somente em uma sociedade na qual não exista desigualdade social nem expropriação do trabalho ou qualquer outra forma de exploração e de dominação. Ou seja, a verdadeira democracia implica a existência de uma sociedade sem qualquer forma de dominação e sem qualquer máscara ou simulação. Um sistema político efetivamente democrático supõe a criação de uma nova ordem social e política, que supere a separação entre forma e conteúdo própria da democracia burguesa, ou seja, que nasça da superação da sociedade capitalista. Trata-se de uma possibilidade cada vez mais distante ante os novos mecanismos de controle ideológico criados a partir das novas tecnologias de comunicação.

Nunca se insistiu tanto que vivemos em uma "sociedade do conhecimento" e nunca se viveu antes numa sociedade na qual o conhecimento fosse tão concentrado em poucas mãos. No período medieval, por exemplo, o conhecimento se concentrava nos conventos e a formação da elite dirigente ficava explícita no relacionamento social. Hoje o conhecimento se enclausura em centros de pesquisa e é veiculado em produtos consumidos cotidianamente, sem que qualquer um saiba quem detém o saber desta produção. Se tivermos em conta que em torno de duzentas corporações detém metade da riqueza produzida na sociedade, entende-se o quanto o conhecimento tornou-se poder efetivo de controle social, de expropriação do trabalho e de dominação política, situação para a qual servem as novas tecnologias e a concentração do saber em poucas mãos para preservar seus interesses econômicos.

As novas tecnologias de produção e de comunicação, que poderiam ser instrumentos de socialização do saber, no contexto de uma sociedade que concentra riquezas e amplia a desigualdade social, tornam-se mecanismos que contribuem para levar ao extremo as formas de dominação econômica, política e ideológica. Há cerca de três décadas, quando a internet começou a fazer parte do cotidiano nos grandes centros urbanos e apareceu como a novidade democrática de comunicação, não se tinha, ainda, a dimensão controladora deste meio no processo de formação do senso comum. O que não aparecia imediatamente aos entusiastas destes mecanismos, é a forma de comunicação a partir da construção de perfis psicológicos delineados nas redes sociais e que incentivam uma comunicação por emoções e não por sentimentos ou, ainda menos, por conhecimento efetivo, produzido por raciocínios lógicos (ou dialéticos), base da formação de todo conhecimento.

\begin{tabular}{|c|c|c|c|c|}
\hline Qovista Oialeatus & Ano 4 & n. 10 & Janeiro - Julho 2017 & p. 24-45 \\
\hline
\end{tabular}


Neste contexto, as condições de um pensamento crítico, fundamental para a concretização de uma verdadeira democracia a partir da elevação do nível cultural do senso comum, se esvaem e as comunicações interpessoais e também as políticas se reduzem ao nível do cotidiano imediato, abstrato e superficial. Os políticos de plantão já perceberam a grande fonte de manipulação ideológica e política que se encontra nas redes sociais, tanto que as campanhas eleitorais e as promessas de campanha se baseiam nos perfis psicológicos identificados nestas redes.

Por se efetivarem com base em emoções, as comunicações veiculadas nas redes não se apoiam em um projeto político especifico, tendo a característica aparente de ausência de qualquer projeto de vida ou de sociedade. Porém, um projeto existe, o de conservar o sistema vigente e transformar estes mecanismos em eficientes instrumentos de controle social.

A partir deste contexto, precisamos explicitar a importância e o significado da formação humana, enquanto possibilidade de gerar a perspectiva de um futuro em uma sociedade nihilista e que não oferece futuro às novas gerações, a não ser aquele de se inserir e de se acomodar a este sistema societário. Cabe-nos refletir sobre a perspectiva educativa da sociedade, no sentido de criar laços de pertencimento em uma sociedade que prima por um individualismo exacerbado. As novas gerações precisam superar a imediaticidade, pertencer e participar de grupos com objetivos claros, sentir saudade de algo mais importante que a mera repetição do mesmo no cotidiano desta sociedade.

\section{Notas sobre a formação humana:}

A sociedade moderna, nascida da Revolução Francesa, também produziu um conceito de formação humana, enquanto formação ideal para a vida. Se relembrarmos Heine (1991, p. 89-97), que acentua a relevância dos alemães na sua contribuição filosófica: enquanto os franceses, "moderados e dóceis", (...) “puderam no máximo matar um rei que já havia perdido a cabeça antes que vocês o decapitassem”, os alemães, representados por Kant, tomaram "o céu de assalto" destruindo "os fundamentos da existência de Deus”. Porém, esta façanha da razão especulativa passa por uma reformulação ao se considerar os estragos que ela faria no senso comum: na Crítica da Razão Prática Kant reabilita a figura de Deus, confirmando a necessidade da crença no modo de pensar comum. O que Heine acentua é que a elite de intelectuais alemães não conseguiu superar a separação entre teoria e prática ficando no âmbito da

\begin{tabular}{|l|l|l|l|l|}
\hline Q Rovista Dialectus & Ano 4 & n. 10 & Janeiro - Julho 2017 & p. 24-45 \\
\hline
\end{tabular}


história das ideias sem criar, assim, as condições para a revolução efetiva.

O conceito de formação cultural (Bildung) também se apresenta como uma das grandes contribuições do pensamento alemão para o processo educativo moderno. De certo modo, a educação apresenta-se como um processo formativo, tanto que se definia a educação como formação humana integral, com um acento no sentido qualitativo e ético. Este conceito tem raízes na tradição alemã, com forte expressão nas Críticas kantianas, que afirmam a centralidade da razão nos critérios de validade do conhecimento, no princípio do dever e da eticidade, assim como no compromisso de aperfeiçoamento e elevação cultural. O "humano" tem, assim, a característica da racionalidade como fonte de conhecimento e busca da verdade, de autonomia do sujeito (sem o coletivo), enquanto a "formação" se traduz na elevação cultural, aperfeiçoamento do caráter, elevação ética e estética, sempre do sujeito individual.

No contexto da sociedade burguesa o ideal de formação se delimita pelo individualismo, nascido tanto da ideia de um sujeito isolado e fechado em si (Kant), quanto de todas as teorias liberais que formaram o senso comum ao longo da existência desta sociedade. Neste contexto, a formação se reduz ao modo como um indivíduo se aperfeiçoa no âmbito da cultura burguesa, ou seja, da cultura produzida ou apropriada no seio de uma sociedade marcada pela divisão social do trabalho, com uma perspectiva de classe que é ocultada por uma pretensão de neutralidade do projeto civilizatório que se implementou.

Esta se torna a perspectiva burguesa de educação visto que, não colocando em questão a divisão social do trabalho e a desigualdade dela decorrente, torna-se o projeto de educação das elites, daqueles que são efetivamente preparados para se tornarem dirigentes. Questionar esta ideia de formação humana implica, portanto, fazer a crítica da estrutura social e da cultura burguesa e, para tal, temos que retomar novamente Marx.

Um dos escritos fundamentais para abordar este tema é Sobre a Questão Judaica, publicado em 1844. Trata-se de um artigo que se coloca entre A Crítica à filosofia do direito de Hegel (1843) e Sobre a Crítica da Filosofia do Direito de HegelIntrodução (1844), que abordamos acima. Aborda a estrutura do Estado burguês e a forma como se produzem as ideias de cidadania e emancipação política no contexto deste Estado, bem como dos limites destes conceitos no conjunto das relações sociais e políticas burguesas.

O debate no qual o artigo se insere coloca em questão a relação contraditória

\begin{tabular}{|l|l|l|l|l|}
\hline Q Rovista Dialectus & Ano 4 & n. 10 & Janeiro - Julho 2017 & p. 24-45 \\
\hline
\end{tabular}


entre Estado e religião, salientando as características específicas da situação histórica alemã. A partir deste contexto, Marx explicita as condições necessárias para uma emancipação política, situação que implica a emancipação humana: um Estado livre exige que o homem se liberte: a emancipação humana supõe a superação da religião enquanto ideologia. Tem-se aqui, implicitamente, a colocação que se esclarece em Sobre a Crítica da Filosofia do Direito de Hegel - Introdução: a "exigência de abandonar as ilusões sobre uma situação é a exigência de abandonar uma situação que necessita de ilusões" (MARX, 2009, p.475); o homem precisa libertar-se dos grilhões, descer do céu para a terra, ou seja, a emancipação política pressupõe a identificação e a superação da ideologia que sustenta as relações sociais e políticas, para compreender, agir e transformar a realidade.

O tema do artigo Sobre a Questão Judaica acentua que a emancipação humana apresenta-se como uma condição para uma formação verdadeiramente humana. Esta reflexão de Marx se aprofunda ao longo de seus estudos: a formação precisa fazer-se como crítica e superação das contradições que permeiam a realidade social e política, ou seja, no contexto da sociedade burguesa, ideias como "liberdade", "direito", "cidadania" apresentam limites que as tornam parte das ilusões a serem superadas.

Todo o modo de pensar e de ser na sociedade burguesa é delimitado pela redução de tudo ao individual isolado e a um entendimento parcial e naturalizado dos conceitos. A transformação das condições materiais de existência exige que, concomitantemente, se transforme o modo de pensar, superando tanto as contradições reais quanto as que agrilhoam o nosso pensamento.

A liberdade equivale ao direito de fazer e promover tudo que não prejudique a nenhum outro homem. O limite dentro do qual cada um pode mover-se de modo a não prejudicar o outro é determinado pela lei do mesmo modo que o limite entre dois terrenos é determinado pelo poste da cerca. Trata-se da liberdade do homem como mônada isolada recolhida dentro de si mesma (MARX, 2010, p. 49).

E Marx segue com outros exemplos de como os conceitos são delimitados e determinados pelo modo como se estrutura a sociedade capitalista, fator que se desdobra no processo educativo de formação do indivíduo isolado, fechado em si como uma mônada, base para as posteriores relações competitivas que compõe todo o sistema produtivo e que Marx elucida no curso de seus escritos. Gramsci retoma esta leitura para explicitar como, na formação do senso comum, esta representação dos conceitos

\begin{tabular}{|l|l|l|l|l|}
\hline Rovista Dialectus & Ano 4 & n. 10 & Janeiro - Julho 2017 & p. 24-45 \\
\hline
\end{tabular}


apresenta uma função política precisa: aceitar passivamente a ordem estabelecida.

Portanto, falar de formação humana implica explicitar os pressupostos que delimitam esta formação no contexto da sociedade capitalista e, principalmente, acentuar que Marx já mostrava no escrito de 1844 que a emancipação da sociedade estava nas mãos do proletariado: uma classe com "grilhões radicais", que possui "caráter universal por meio de seus sofrimentos universais" (...) e que não pode se emancipar sem estender esta emancipação a toda a sociedade (MARX, 2009, p. 488). E falando da revolução alemã, Marx acentua já nestes escritos que esta emancipação universal, pressuposto para uma emancipação política, pode ser efetivada somente por uma classe que não tenha privilégios a defender e que, ao contrário, se encontre numa situação de extrema exploração material.

Em A Ideologia Alemã as características desta revolução se esclarecem: trata-se de uma revolução que precisa abolir todas as formas de dominação relativas a todas as classes sociais, transformação prática que precisa criar um novo homem, ou seja, realizar efetivamente a emancipação humana (MARX, 1976). Importante frisar que não se trata de mudar as ideias, mas de transformar dialeticamente a existência material e, com ela, transformar ao mesmo tempo o modo de pensar e de ser. Gramsci aborda esta questão em vários momentos dos Cadernos, dos quais retomamos o fragmento 2 do Caderno 10: “A questão é sempre a mesma: o que é o homem? O que é a natureza humana? Se se define o homem como indivíduo, psicológica e especulativamente", o problema apresenta-se como puramente verbal. Porém, "se se concebe o homem como um conjunto de relações sociais", descobre-se que toda "comparação no tempo é impossível, porque se trata de coisas diversas e heterogêneas". Se considerarmos, por outro lado, que o "homem é também o conjunto de suas condições de vida, se pode medir quantitativamente a diferença entre o passado e o presente", ou seja, a estabelecer a "medida em que o homem domina a natureza e o acaso" (GRAMSCI, 1978, p. 1337). A partir do estatuto do humano no modo como o homem cria a sua vida a partir do modo como domina a natureza, supera suas necessidades básicas, gera novas possibilidades sociais, Gramsci define o homem (e implicitamente o humano) como "liberdade":

A medida da liberdade entra no conceito de homem. Que existam as possibilidades objetivas de não se morrer de fome e que, no entanto, se continue a morrer de fome, tem sua

\begin{tabular}{|l|l|l|l|l|}
\hline Ronista Dialectus & Ano 4 & n. 10 & Janeiro - Julho 2017 & p. 24-45
\end{tabular}


importância, ao que parece. Mas a existência das condições objetivas, a possibilidade ou liberdade não são ainda suficientes: é necessário "conhecê-las" e saber utilizá-las. Querer utilizá-las. O homem, neste sentido, é vontade concreta, ou seja, aplicação efetiva do querer abstrato ou do impulso vital aos meios concretos que realizam tal vontade (Q. 10, p. 1338).

Podemos dizer a partir desses pressupostos que a "liberdade" não pode ser entendida apenas como elemento subjetivo individual, na base do individualismo liberal que forma o senso comum; a liberdade se cria na medida em que se efetiva a relação entre teoria e prática no movimento de produção da vida. Não basta que existam as condições objetivas, faz-se necessário que todos tenham acesso a elas e, para tanto, fazse necessário "conhecê-las", ou seja, criar os meios concretos de realização da vontade, tomar consciência (política) dos direitos sociais, organizar-se para efetivar estes direitos em uma nova ordem social e política.

O homem ativo, de massa, atua praticamente, mas não tem uma consciência teórica clara da sua ação que, no entanto, é um conhecimento do mundo na medida em que o transforma. A consciência teórica pode, inclusive, estar historicamente em contradição com o seu agir. Pode-se quase dizer que ele tem duas consciências teóricas (ou uma consciência contraditória): uma implícita na sua ação e que realmente o une a todos os seus colaboradores na transformação prática da realidade e uma superficialmente explícita ou verbal, que herdou do passado e acolheu sem crítica (GRAMSCI, 1978, Q. 10, p. 1385).

O pressuposto para superar esta consciência superficial, acolhida sem crítica, que faz parte do senso comum e se traduz em conceitos abstratos e naturalizados é, conclui Gramsci, na senda aberta por Marx, a organização política das classes trabalhadoras, a luta de classes em todas as suas dimensões. Cabe aprofundar a compreensão das relações econômicas, sociais, políticas e ideológicas e seus desdobramentos na atual fase do capitalismo.

Gramsci recomenda "aprofundar o conceito de unidade entre teoria e prática" que, no caso da realidade de 1930, apresentava-se "ainda em fase inicial" (Q. 10, p. 1386). Neste contexto, a consciência de classe ainda em formação no movimento político, pode sofrer influências deterministas e reformistas que delineiam o modo de compreender as lutas: quando "não se tem a iniciativa na luta e a própria luta termina por identificar-se com uma série de derrotas", abre-se o caminho para o determinismo

\begin{tabular}{|l|l|l|l|l|}
\hline Govista Dialectus & Ano 4 & n. 10 & Janeiro - Julho 2017 & p. 24-45 \\
\hline
\end{tabular}


mecânico que se torna "uma força formidável de resistência moral, de coesão, de perseverança paciente e obstinada" (Q. 10, p. 1388).

A vontade real se disfarça em ato de fé numa certa racionalidade histórica, em uma forma empírica e primitiva de finalismo apaixonado... [...] a consciência é contraditória, falta uma unidade crítica, etc. Mas quando o "subalterno" torna-se dirigente e responsável pela atividade econômica de massa, o mecanicismo aparece, em certo ponto, em perigo iminente e acontece uma revisão em todo o modo de pensar porque aconteceu uma mudança no modo social de ser (Q. 10, p. 1388).

O movimento de luta de classes, de organização operária é a base, para Gramsci, de qualquer mudança no modo de pensar a partir de um pensamento crítico. Portanto, falar de formação humana implica explicitar os limites políticos e ideológicos da sociedade capitalista no processo de expropriação do trabalho, nas várias formas de dominação existentes e que caracterizam as mais variadas formas de barbárie que se reproduzem nesta sociedade.

\section{Conclusão:}

Ao mostrar os limites da democracia e da formação humana no contexto da sociedade capitalista acentua-se que: a superação destes limites só é possível com uma mudança estrutural desta sociedade, que tem no horizonte a luta de classes e a organização política do proletariado. A releitura dos escritos de Marx publicados entre 1843-1844, já apresentam implicitamente a proposição de que a transformação radical da sociedade moderna se encontra nas mãos do proletariado; este entendimento se explicita no curso da vida de Marx concretizando-se em $O$ Capital. Da retomada de alguns pontos dos primeiros escritos nos voltamos para a leitura de Gramsci em suas análises do Estado burguês, dos limites da democracia e das possibilidades de sua superação no processo de organização política das classes trabalhadoras.

Um dos caminhos proposto por Gramsci é a crítica e superação dos limites ideológicos do senso comum, visto que as novas dimensões da luta de classes exigem articular economia, política e ideologia, a fim de superar as novas formas de dominação ideológica. Esta proposição implica acentuar a importância do processo educativo na sua ampla dimensão de formação de uma nova concepção de mundo. Para tanto, cabe partir da realidade empírica, explicitar os limites seus limites reconhecendo as

\begin{tabular}{|l|l|l|l|l|}
\hline Q Rovista Dialectus & Ano 4 & n. 10 & Janeiro - Julho 2017 & p. 24-45 \\
\hline
\end{tabular}


contradições que permeiam o social e criticar o senso comum a fim de torná-lo coerente e unitário, gerando as possibilidades de romper com os limites ideológicos que condicionam a vida na sociedade capitalista. Este aprendizado pedagógico pode se realizar somente no contexto da organização política dos trabalhadores no âmbito da luta de classes, a partir da qual se pode reconhecer a origem e a formação do senso comum, os seus limites na abstração e naturalização dos conceitos e as possibilidades de crítica e de formação para uma nova ordem social e política na qual, a partir de novas relações econômicas e sociais, se poderá, finalmente, construir os caminhos para a efetiva formação humana.

\section{Referências:}

BURGIO, Alberto. Gramsci: il sistema in movimiento. Roma: Derive-Approdi, 2014.

GRAMSCI, Antonio. Quaderni del Carcere. Torino: Einaudi, 1978.

HEINE, H. Contribuição à história da religião e filosofia na Alemanha. São Paulo: Iluminuras, 1991.

MARX, Karl. Sobre a Crítica da Filosofia do Direito de Hegel. Introdução. In: MARCAL, Jairo (Org.). Antologia de textos filosóficos. Curitiba: SEED-PR, 2009, pp. 474-489.

MARX, Karl. Sobre a Questão Judaica. São Paulo: Boitempo, 2010.

MARX, Karl. Para a Crítica da Economia Política (Prefácio de 1859). In: Pensadores, Abril Cultural, 1974, pp. 133-138.

MARX, Karl e ENGELS, Friedrich. A Ideologia Alemã I - crítica da Filosofia alemã mais recente. Lisboa: Editorial Presença, 1976.

MARX, K. O 18 Brumário de Luís Bonaparte. Rio de Janeiro: Paz e Terra, 1977. Crítica da filosofia do direito de Hegel. Lisboa: Presença, [s.d].

\begin{tabular}{|l|l|l|l|l|}
\hline Q Rovista Dialectus & Ano 4 & n. 10 & Janeiro - Julho 2017 & p. 24-45 \\
\hline
\end{tabular}

